\title{
Construction of Experiment Teaching on Computer Network Course
}

\author{
Ping Qi \\ College of Computer \& Communication Engineering, \\ China University of Petroleum, \\ Qingdao 266555, China \\ e-mail: zhqip@upc.edu.cn
}

\author{
Le Yi Shi \\ College of Computer \& Communication Engineering, \\ China University of Petroleum, \\ Qingdao 266555, China
}

\begin{abstract}
As the practice link of computer network theoretical teaching, experiment teaching of computer network can improve students' operating ability and deepen their understanding principle of this course. Simple technology and method of operating network can't meet learning demand of students and for purpose of training students' ability, so it is necessary to establish experiment content suited to them mostly on the basis of syllabus and mastery degree of related knowledge. Therefore this paper proposes a study pattern including five processes of "cognition-familiarity-simulationverification-design" on principle of network bottom layer, and formulates continuous and interlocking experiment content which can make students possess independent design ability.
\end{abstract}

Keywords- network experiment course; study pattern; socket programming; experimental teaching reform

\section{INTRODUCTION}

With rapid development and widely application of computer technology, computer network has seeped into every fields of daily life and application examples of network technology combined with communication can be experienced by people everywhere. As a result, professionals having outstanding network principle, technology skills, comprehensive application and innovation ability will be needed urgently by society. Computer network technology has a high requirement for principle and practice, and in order to grasp inner mechanism really, students must go through strict laboratory exercise based on mastering various protocols and algorithms.

Not having support of experiment, the students will be given a abstract study effect on variety of protocols and theory, therefore the construction of the experimental environment and design of reasonable experimental content will allows students to get an deep understanding of the theoretical knowledge, and at the same time can raise students' practice and analyze ability to achieve the last aim of having certain innovation thinking. Computer network course has a very importance in computer professional teaching which can be verified by the fact computer network is selected as a postgraduate entrance examination course by Ministry Education in 2009. "The Outline of Educational Development" also pointed out that information technology have an important impact on education development and must be pay high attention to it. Yet, information society is built on bottom of computer network and it has become a principal character of the current society.

\section{THE CURRENT STATE}

The experimental content of computer network is composed of network principle experiment, network operate system experiment, network formation experiment, network security experiment, network manager experiment, network application and development experiment. These contents relate to complex hardware and software structure. Hardware environment consists of a number of computers, transmission medium, modems, routers and other network interconnection equipments; software environment includes network operate-system, network database system, network manager system and other software. Above mentions illustrate a situation of network experiment: it has special complex compared with other courses and only by experiment study and practice, students can comprehend work principle of network better instead of defect on only applying network.

By investigation and communication with teachers of network profession, an efficient teaching pattern emerges: many network courses adopt the same "Computer Network" teaching material published by Electronics Industry Press, but various teachers use different experiment content. For example, some content stress configure practice about network hardware, some content mainly teach data package of various network protocols and some emphasizes editor train using page language. This paper propose a teach reform with the purpose of devising the most suitable network experiment content according to our syllabus and actual situation of our school students.

\section{DESIGN IDEAS OF EXPERIMENT CONTENT}

As a senior course of computer major, computer network course prevent students from being in the layer of only applying network, the real teach aim is make students get the deep insight into the connotation technology of network system integration and firsthand experience of construction, manager, maintenance of network system, and be aware of how to use various network protocols.

Cisco network basic course is a major course of computer professional students; this course mainly teaches the configuration of process of network routers and switchboard, network planning and router protocol configuration. Hence, network experiment content stresses programming teaching by using raw socket to make students understand the most basic knowledge of network. This 
teaching method can be seen as a complementary with Cisco courses and a good pattern to excise students' operation ability of network. More importantly, this can bring students more study interest and make themselves providers of network services. As we know, saw socket is basis of communication and are basic operation unit of network communication supporting TCP/IP protocols. The reason of selecting raw socket programming instead of standard socket is the former may read or write IP data packet not dealing with by core, the streaming socket only can handle TCP protocols data and datagram socket only handle UDP protocols data.

In general, experiment content of computer network includes two parts: one is basic and confirmatory experiment carried out to simulate and verify principals, and the other is integrity and designing experiment in which students are main body to accomplish overall design scheme in accordance with experiment condition and requirement. Following this idea, this paper proposes such eight steps study pattern as "cognition-familiarity-simulationverification-design".

\section{Step 1}

Understand composition and structure of network and achieve a simple topology of network. Teachers can guide students make a variety of network connection according to topology diagram to connect PC, routers, switchboards with them to cause the network work and by simple configuration. By this step, students can learn function and position of every network devices; as a result, they can have a distinct cognitive process.

Step 2

Realize the relationship between services and clients. By programming simple software and run on PC machines, students can comprehend the process of communication operating with the help of network connection among services and clients.

\section{Step 3}

Set up MAIL, FTP, WWW services in Linux system. On basis of configuration of network services provided by Linux system, students can furthermore know well all kinds of services function and parameters setting supported by them. Meanwhile, they can further acquire the aims achieved by services providers.

\section{Step 4}

Make use of MAIL services and use command word to send and receive mail. This step is a consequent process and it not only review previous content but also prepares the next experiment content. This step can improve students' adaptability no matter experiment content is changed.

Step 5

Realize client software with functions of sending and receiving mail. By studying command word, it is easy for students to simplify and realize functions of sending and receiving mail by socket programming. In this phase, no matter how complex the program designs are needed students realize, the only thing require students to master work theory is to accomplish send and receive mail. This step is also the simulation phase.

\section{Step 6}

Use some software such as SNIFFER capture data packet communicated in network transmission and analyze type or parameters of protocols. Specially, this step is also used to make students understand packet types of various data packets, be familiar with three-way hand shake mechanism, verify certain content of principal part. This step is very critical for overall steps because it relates two contents which will be taught in next parts. Two sub-steps are included in this step: one is by some methods to guide students discuss work principle of SNIFFER; the other is let them learn thoroughly the packet form. During initial study phase, forms of data package, core algorithms, operation mechanism are three continuous parts in computer course.

\section{Step 7}

Realize function of grasp packets. On basis of previous content, students can achieve software which functions of grasping packets. By this step, students can get a impressive understanding of working principle of bottom of network.

\section{Step 8}

Realize flooding attack in local area network. This is the last experiment content. As a design process, its main aim is to make students master skillfully encapsulation mechanism of data packet. Note that this step is required a closed local area network and the harm result may caused by this experiment must inform student, otherwise, campus network will be attacked unconsciously.

These eight experiments are all achieved in Linux environment by use of GCC compile tools. On the whole, these experiments will lead students to palace of network world from phase of understanding to knowing well by abstract concepts and concrete program examples.

\section{PONDERING OF EXPERIMENT TEACHING REFORM}

Excellent laboratory configuration and good experiment teaching system are the support platform for reform of computer network course. For some aspects of perfecting experiment teaching and course system, we can follow such methods as:

\section{Coordination between theory and experiment}

The teach aim of network experiment is to improve students quality of scientific experiment, innovation and engineering practice ability. The task of experiment teaches is accomplished by setting up basic, comprehensive, exploratory experiment items to cultivate ability of design, manager and application; furthermore, it also can improve integrated skills. As we know, theory knowledge can guide practice and problems occurred in experiments will promote students seek answers of some theory questions. In this layer sense, it can embody coordination between theory and experiment. So, during design experiment syllabus, some 
factors such implementations plans as express method of progressiveness, feasibility of theory and practice. Meanwhile, a evaluation system must be draw up which is systematic, reasonable, operable.

\section{Coordination between teach content and syllabus}

Experiment teach is not objectless and it need conform to syllabus. In other words, experiment content is defined by referring to cultivation aim and seen as efficient supplement for theory teaching; the real aim of experiment teach is strengthen practical and creational thinking and the ability of applying theory to practice.

\section{Opening experiment project}

There are some limitations which exist in experiment content operating during classroom teaching. All experiment content connected with theory cannot be completed during limited class time. So, some network experiment content can be used as open project as competition for classroom experiment; in these environment, students can select special experiment content according to their spare time or requirement for purpose of expanding and perfecting their knowledge scope.

With reform of network experiment content, general experiment content is enriched with hardware, software, operation, verification, analysis, design process. For IT major, this transfer is from current simulation software experiment and network services application program to raw socket one using open source Linux system. In this circumstance, the knowledge required in these experiments become more professional and the requirement are more improved. Meanwhile, this reform mode can be seen as the conversion from simply simulating network application to analyzing network structure especially to bottom protocol program which is more deep and professional.

\section{SUMMARY}

This series of network experiment contents have applied to 180 communication major students. The questionnaire survey shows that this content improve student's network practice ability by continuous steps. Because these experiments need $\mathrm{C}$ programming environment in Linux system, it also shows some limitations such as: Firstly, students must be familiar with Linux operation system; secondly, they must know well C program. Considering these related courses have been opened in syllabus, so some adjustment are made to avoid this courses cannot carry out because of lacking of those knowledge. Computer network technology is changing continuously and experiment content require be adjusted finely, only by this reform thoughts, network experiment course can more conform to teach syllabus and requirement of students to master network knowledge.

\section{REFERENCES}

[1] Nie ya,Zheng wei. Computer Network Experiment Teaching and Design. Silicon Valley, No.11 2009 : 161-162.

[2] Yang ying,Song ling.Computer network experiment teaching reform and Thinking. Journal of Guangxi University(Philosophy and Social Science), Vol.24 S1 : 99-100.

[3] Heng Yang Luo. Analysis of computer network experiment teaching mode. Popular science and technology. 2010 No.7 : 173-174

[4] DUAN Pei-Jun. The Exploration and Practice of Experimental Teaching Based on Network Technology[J]. Research and Exploration in Laboratory, 2006,25(12):1481-1487.

[5] Xi Ren Xie. Computer Network (The Fifth Edition) Electronic Industry Press 2008.

[6] SHI Leyi, QI Ping. Practice on Raw Socket Programming for Network Experiments, Computer Education, No.23 2010.12, 105-107. 